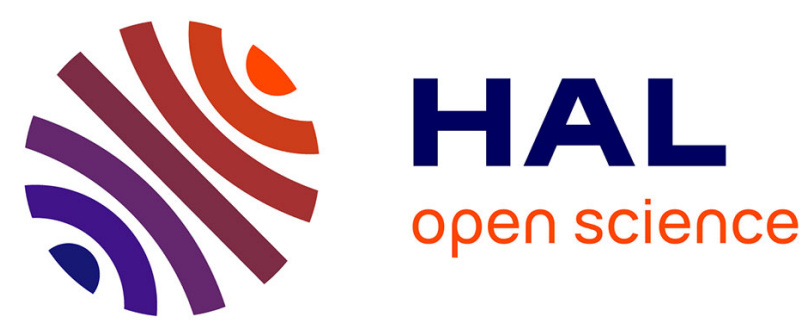

\title{
Effectiveness and safety of ustekinumab induction therapy for 103 patients with ulcerative colitis: a GETAID multicentre real-world cohort study
}

Aurelien Amiot, Jerome Filippi, Vered Abitbol, Guillaume Cadiot, David Laharie, Melanie Serrero, Romain Altwegg, Yoram Bouhnik, Laurent Peyrin-Biroulet, Cyrielle Gilletta, et al.

\section{To cite this version:}

Aurelien Amiot, Jerome Filippi, Vered Abitbol, Guillaume Cadiot, David Laharie, et al.. Effectiveness and safety of ustekinumab induction therapy for 103 patients with ulcerative colitis: a GETAID multicentre real-world cohort study. Alimentary Pharmacology and Therapeutics, 2020, 51 (11), pp.1039-1046. 10.1111/apt.15717 . hal-02798010

HAL Id: hal-02798010

https://hal-univ-rennes1.archives-ouvertes.fr/hal-02798010

Submitted on 17 Jul 2020

HAL is a multi-disciplinary open access archive for the deposit and dissemination of scientific research documents, whether they are published or not. The documents may come from teaching and research institutions in France or abroad, or from public or private research centers.
L'archive ouverte pluridisciplinaire HAL, est destinée au dépôt et à la diffusion de documents scientifiques de niveau recherche, publiés ou non, émanant des établissements d'enseignement et de recherche français ou étrangers, des laboratoires publics ou privés. 


\section{AP\&T}

\section{Alimentary Pharmacology and Therapeutics}

\section{Effectiveness and safety of ustekinumab induction therapy for 103 patients with real-world ulcerative colitis: A GETAID multicentre cohort study}

\begin{tabular}{|c|c|}
\hline Journal: & Alimentary Pharmacology \& Therapeutics \\
\hline Manuscript ID & APT-0048-2020.R2 \\
\hline Wiley - Manuscript type: & Original Scientific Paper \\
\hline $\begin{array}{r}\text { Date Submitted by the } \\
\text { Author: }\end{array}$ & 18-Mar-2020 \\
\hline Complete List of Authors: & $\begin{array}{l}\text { AMIOT, Aurélien } \\
\text { Filippi, Jerome } \\
\text { Abitbol, Vered; Hopital Cochin, Gastroenterology } \\
\text { Cadiot, Guillaume; CHU Robert Debré, Hépato-Gastroentérologie } \\
\text { Laharie, David; CHU de Bordeaux, Gastroenterologie } \\
\text { Serrero, Melanie } \\
\text { Altwegg, Romain; University Hospital of St Eloi, Department of } \\
\text { Hepatology and Gastroenterology } \\
\text { Bouhnik, Yoram; Hopital Beaujon, Department of Gastroenterology, IBD, } \\
\text { Intestinal failure and Intestinal transplantation; APHP, } \\
\text { Peyrin-Biroulet, Laurent } \\
\text { Gilletta de Saint Joseph, Cyrielle; Universite Toulouse Jean Jaures, } \\
\text { Departement of gastroenterology and hepatology } \\
\text { Roblin, Xavier } \\
\text { Pineton De Chambrun, Guillaume; Montpellier University, } \\
\text { Gastroenterology } \\
\text { Vuitton, Lucine } \\
\text { Bourrier, Anne } \\
\text { Nancey, stephane; University hospital Lyon Sud; France, } \\
\text { Gastroenterology } \\
\text { Gorrnet, Jean-Marc; Hospital Saint-Louis, Gastroenterology } \\
\text { NAHON, Stephane; Centre Hospitalier Le Raincy-Montfermeil, Service } \\
\text { d'hépatogastroenterologie } \\
\text { Bouguen, Guillaume; Hôpital Pontchaillou, Service des Maladies de } \\
\text { l'Appareil Digestif; INSERM U991, université de Rennes } 1 \\
\text { Viennot, Stéphanie; CHU de Caen, Hépato-Gastro-Entérologie et } \\
\text { Nutrition } \\
\text { Pariente, Benjamin; Gastroenterology Department, Claude Huriez } \\
\text { Hospital, University of Lille 2,; Inserm UMR 995 LIRIC, Lille University } \\
\text { Fumery, Mathurin; Amiens University Hospital, Hepatogastroenterology }\end{array}$ \\
\hline Keywords: & $\begin{array}{l}\text { Inflammatory bowel disease < Disease-based, Ulcerative colitis }< \\
\text { Disease-based, Large intestine < Organ-based, Immunosuppression }< \\
\text { Topics }\end{array}$ \\
\hline
\end{tabular}




\section{SCHOLARONE ${ }^{\text {m }}$ Manuscripts}




\section{Editing Certificate}

This document certifies that the manuscript

Effectiveness and safety of ustekinumab induction therapy for real-world ulcerative colitis: A GETAID multi-centre cohort study

prepared by the authors

Aurélien Amiot, Jérôme Filippi, Vered Abitbol, Guillaume Cadiot, David Laharie, Melanie Serrero, Romain Altwegg, Yoram Bouhnik, Laurent...

was edited for proper English language, grammar, punctuation, spelling, and overall style by one or more of the highly qualified native English speaking editors at AJE.

This certificate was issued on January 6, 2020 and may be verified on the AJE website using the verification code 7B0D-C15E-8951-58B8-D104 .

Neither the research content nor the authors' intentions were altered in any way during the editing process. Documents receiving this certification should be English-ready for publication; however, the author has the ability to accept or reject our suggestions and changes. To verify the final AJE edited version, please visit our verification page at aje.com/certificate. If you have any questions or concerns about this edited document, please contact AJE at support@aje.com.

AJE provides a range of editing, translation, and manuscript services for researchers and publishers around the world. For more information about our company, services, and partner discounts, please visit aje.com. 


\title{
Title: Effectiveness and safety of ustekinumab induction therapy for 103 patients with real- world ulcerative colitis: A GETAID multicentre cohort study
}

\section{Short title: Ustekinumab induction for UC}

\begin{abstract}
Authors: Aurélien Amiot ${ }^{1}$, Jérôme Filippi ${ }^{2}$, Vered Abitbol ${ }^{3}$, Guillaume Cadiot ${ }^{4}$, David Laharie ${ }^{5}$, Melanie Serrero ${ }^{6}$, Romain Altwegg 7 , Yoram Bouhnik ${ }^{8}$, Laurent Peyrin-Biroulet ${ }^{9}$, Cyrielle Gilletta $^{10}$, Xavier Roblin ${ }^{11}$, Guillaume Pineton de Chambrun ${ }^{7}$, Lucine Vuitton ${ }^{12}$, Anne Bourrier ${ }^{13}$, Stephane Nancey ${ }^{14}$, Jean-Marc Gornet ${ }^{15}$, Stephane Nahon ${ }^{16}$, Guillaume Bouguen ${ }^{17}$, Stephanie Viennot $^{18}$, Benjamin Pariente ${ }^{19}$, and Mathurin Fumery ${ }^{20}$ on behalf of the UC-USK-GETAID study group.
\end{abstract}

1. Department of Gastroenterology, Henri Mondor Hospital, APHP, EC2M3-EA7375, Paris EstCréteil Val de Marne University, Creteil, France

2. Nice, France

3. Cochin Hospital, Paris, France

4. Reims, France

5. Bordeaux, France

6. Marseille, France

7. Montpellier, France

8. Clichy, France

9. Nancy, France 
10. Toulouse, France

11. Saint-Etienne, France

12. Besançon, France

13. Saint-Antoine Hospital, Paris, France

14. Lyon, France

15. Saint-Louis Hospital, Paris, France

16. Montfermeil, France

17. Rennes, France

18. Caen, France

19. Lille, France

20. Amiens, France

All the members of the UC-USK-GETAID study group are listed in the appendix.

Abstract: 250 words

Word count: 2890 words (excluding the abstract and references)

Please address correspondence and reprint requests to:

Docteur Aurelien AMIOT 
51, Avenue du Marechal de Lattre de Tassigny CRETEIL F-94010 - France

Universite Paris Est Creteil, Henri Mondor University Hospital

Tel: +33-149812362

Fax: +33-149812352

E-mail: aurelien.amiot@hmn.aphp.fr

Keywords: ulcerative colitis; ustekinumab; induction therapy; effectiveness; safety.

Abbreviations: UC: Ulcerative colitis; CRP: C-reactive protein ; PRO: patient reported outcome ; UCEIS: Ulcerative Colitis Endoscopic Index of Severity

\section{Conflicts of interest:}

Aurelien Amiot received consulting fees from Abbvie, Hospira, Janssen, Tillotts, Pfizer, Takeda, Gilead and Biocodex as well as lecture fees and travel accommodations from Abbvie, Janssen, Biocodex, Hospira, Ferring, Pfizer, Ferring, Tillotts, Takeda and MSD. This author also received advisory board fees from Gilead, Takeda and Abbvie.

Jerome Filippi received lecture and consulting fees from Abbvie, Amgen, Astellas pharma, Biogen, Celltrion, Ferring, Janssen, MSD, Pfizer, Sandoz, Takeda.

Vered Abitbol received lecture fees from Biogen Amgen Sandoz Mylan Pfizer Takeda Janssen Gilead Tillots

Guillaume Cadiot received consulting fees from AAA, Ipsen, Keocyt, Novartis and Pfizer and lecture fees from Abbvie, Ferring, Pfizer, Janssen, Takeda. 
David Laharie received counseling, boards or transports fees from Abbvie, Biogaran, Biogen, Ferring, HAC-pharma, Janssen, MSD, Novartis, Pfizer, Prometheus, Roche, Takeda, Theradiag, Tillots.

Melanie Serrero has received lecture fees from Abbvie, Ferring

Romain Altwegg received board or lectures fees from Abbvie, Janssen, Pfizer, Takeda.

Yoram Bouhnik received lecture and consulting fees from Abbvie, Biogaran, BoehringerIngelheim, CTMA, Ferring, Gilead, Hospira, ICON, Inception IBD, Janssen, Lilly, Mayoli Spindler, Merck, MSD, Norgine, Pfizer, Robarts Clinical Trials, Roche, Sanofi, Shire, Takeda, UCB and Vifor Pharma. This author has also stock ownership of Inception IBD, San Diego, CA, USA.

Laurent Peyrin-Biroulet received consulting fees from Merck, Abbvie, Janssen, Genentech, Ferring, Norgine, Tillots, Vifor, Shire, Therakos, Pharmacosmos, Pilège, BMS, UCB-Pharma, Hospira, Celltrion, Takeda, Biogaran, Boerhinger-Ingelheim, Lilly, Pfizer, and HAC-Pharma. This author also received lecture fees from Merck, Abbvie, Takeda, Janssen Cilag, Ferring, Norgine, Tillots, Vifor, Therakos, HAC-Pharma, and Mitsubishi.

Cyrielle Gilletta received lecture fees from Abbvie, Takeda, Pfizer and Janssen and consulting fees from Abbvie, Janssen and Celltrion.

Xavier Roblin reported a relationship with Abbvie, MSD, Janssen Cilag, and Takeda.

Guillaume Pineton de Chambrun received consulting fees from Takeda, Janssen and Tillotts Pharma and lecture fees from Takeda, Abbvie, MSD, Janssen, Tillotts Pharma, Ferring and Pfizer. 
Lucine Vuitton received lecture fees from Abbvie, MSD, Takeda, Ferring, Mayoli, Janssen and Pfizer, and research grants from MSD, Takeda and Pfizer.

Stephane Nancey received consulting fees from Merck, Abbvie, Takeda, Ferring, Norgine, Vifor Pharma, Novartis, Janssen-Cilag, Hospira, Takeda and HAC-Pharma.

Jean-Marc Gornet received fees from Sanofi, Merck Serono, Roche, Novartis, Amgen and travel accommodation from Abbvie and MSD.

Guillaume Bouguen received lecture fees from Abbvie, Ferring, MSD, Takeda and Pfizer and consultant fees from Takeda, Janssen, Sandoz and Mylan.

Stephanie Viennot has received consulting fees from Abbvie, MSD, Takeda, Vifor Pharma and Ferring.

Benjamin Pariente received consulting fees from AbbVie, MSD, Takeda, Janssen, Lilly, Pfizer, Biogaran, Mylan, Sandoz; and lecture fees: Abbvie, MSD, Takeda, Janssen, Mylan, Sandoz, Ferring

Mathurin Fumery has received lecture and consulting fees from Abbvie, MSD, Boehringer, Pfizer, Takeda, Celgene, Gilead, Janssen and Ferring.

No conflicts of interest are claimed by the remaining authors.

Study funding: None.

\section{Author contributions:}

Conception and design of the study: AA, BP, MF 
Generation, Collection, Assembly, Analysis and/or Interpretation of data: AA, JF, VA, GC, DL, MS, RA, YB, LPB, CG, XR, GPdC, LV, AB, SN, JMG, SN, GB, SV, BP, MF

Drafting or revision of the manuscript: AA, JF, VA, GC, DL, MS, RA, YB, LPB, CG, XR, GPdC, LV, AB, SN, JMG, SN, GB, SV, BP, MF

Approval of the final version of the manuscript: AA, JF, VA, GC, DL, MS, RA, YB, LPB, CG, XR, GPdC, LV, AB, SN, JMG, SN, GB, SV, BP, MF 


\begin{abstract}
Background: Phase III trials have demonstrated the efficacy and safety of ustekinumab in moderate-to-severe ulcerative colitis (UC), but few real-life data are currently available.
\end{abstract}

\begin{abstract}
Aim: To assess short-term effectiveness and safety of ustekinumab in patients with UC.
Methods: From January to September 2019, all patients with UC treated with ustekinumab in 20 French GETAID centres were retrospectively included. The primary outcome was steroid-free clinical remission (partial Mayo Clinic score $\leq 2$ ) at weeks 12-16 without a rectal bleeding subscore $>1$.
\end{abstract}

Results: Among the 103 patients included, 70\% had been previously exposed to $\geq 2$ anti-TNF agents and $85 \%$ to vedolizumab. At weeks $12-16$, steroid-free clinical remission and clinical remission rates were $35.0 \%$ and $39.8 \%$, respectively; the absence of rectal bleeding with normal stool frequency was noted in $19.4 \%$ of patients. Two patients discontinued ustekinumab before the week 12-16 visit and underwent surgery. In multivariable analysis, a partial Mayo Clinic score > 6 at inclusion $(18.6 \%$ vs. $46.7 \%, \mathrm{p}=0.003)$ and a history of both exposure to anti-TNF and vedolizumab therapies $(27.3 \%$ vs $80.0 \%, \mathrm{p}=0.001)$ were negatively associated with steroid-free clinical remission at weeks $12-16$. Adverse events occurred in $7.8 \%$ of patients and serious adverse events in $3.9 \%$ of patients.

Conclusion: In a cohort of highly refractory patients with UC with multiple prior drug failures, ustekinumab provided steroid-free clinical remission in one-third of cases at weeks 12-16. Clinical severity and previous use of anti-TNF and vedolizumab therapies were associated with ustekinumab failure at weeks 12-16. 


\section{INTRODUCTION}

Ulcerative colitis (UC) is a chronic inflammatory disease of the large intestine ${ }^{1}$. 5Aminoslicylates, conventional immunosuppressants, tumour necrosis factor (TNF) antagonists and vedolizumab are the main therapeutic agents to obtain clinical and endoscopic remission and prevent disability ${ }^{2}$. These current therapies are limited by increased risks of infection or cancer, as well as by a lack of effectiveness ${ }^{3,4}$. Primary non-response is observed in up to $30 \%$ of patients during anti-TNF or vedolizumab therapies and up to $40 \%$ of patients who initially respond to the induction regimen will subsequently fail to show a response over time ${ }^{5-7}$. There is a growing demand for novel therapeutic agents targeting alternative disease mechanisms.

Ustekinumab (Janssen Biotech Inc., Horsham, PA, United States), a fully human IgG1 monoclonal antibody targeting the IL-12/IL-23 shared p40 subunit, was recently approved for the treatment of psoriasis, psoriatic arthritis, and Crohn's disease. In a phase III trial for the treatment of moderate-to-severe UC, ustekinumab induced a response at 8 weeks and maintained clinical benefit through 52 weeks of treatment in patients who had an inadequate response or unacceptable side effects from corticosteroids, immunomodulators, anti-TNF agents or vedolizumab ${ }^{12}$. This robust data has driven the approval of ustekinumab by the European Medicines Agency for the treatment of patients with moderate-to-severe UC.

Only one study, including 19 patients, have reported the real-world effectiveness of ustekinumab in $\mathrm{UC}^{8}$. Real-world studies allow bridging of some data gaps by describing patient experiences that are lacking in clinical trials that tend to exclude certain groups of patients ${ }^{9-11}$. Real-world experience series bring important data on the effectiveness and safety of new therapeutic options. 
The aim of this study was to evaluate the effectiveness and safety of ustekinumab in a multicentre open-label cohort of patients with UC failing conventional treatment. 


\section{PATIENTS AND METHODS}

\section{Study population}

From January 2019 to September 2019, all French centres affiliated with the Groupe d'Etude Thérapeutique des Affections Inflammatoires du tube Digestif (GETAID) were asked to report consecutive patients with UC treated with ustekinumab. Exclusion criteria were age $<18$ years, total or partial colectomy, or initiation of ustekinumab for an extra-intestinal manifestation. Ustekinumab was administered intravenously at a dose of $6 \mathrm{mg} / \mathrm{kg}$ at week 0 and followed by 90 mg injected subcutaneously every 8-12 weeks according to the investigator's decision and for up to week 16. Subcutaneous induction was also permitted if patients received at least a total dose of $270 \mathrm{mg}$ during the first 8 weeks of treatment. The optimization of ustekinumab therapy at a dose of $90 \mathrm{mg}$ every 4 or 8 weeks was allowed for an insufficient response, according to the investigator's decision. The concomitant use of steroids and/or immunomodulators for UC was recorded at every visit.

The protocol was approved by the Henri Mondor University Hospital Ethics Institutional Review Board (HMN IRB \#00011558). All authors had access to the study data and reviewed and approved the final manuscript.

\section{Data collection}

Investigators from each participating centre were asked to complete a standardized questionnaire. An on-site visit was then conducted to collect missing data from patient records. The recorded data included patient demographics, a detailed account of the UC diagnosis and history, smoking status, UC phenotype according to the Montreal classification, and medical and surgical treatment history. 
All included patients were followed according to routine practice. At the time of introduction of ustekinumab and at the week 12-16 visit, clinical activity was assessed using both the partial and total Mayo Clinic scores ${ }^{12}$. Routine laboratory tests results, including those for leukocyte count, haemoglobin, C-reactive protein (CRP) and albumin, were recorded to assess biological activity. Routine endoscopic assessment at baseline and at weeks 12-16 with the Mayo Clinic endoscopic subscore and Ulcerative Colitis Endoscopic Index of Severity (UCEIS) were also collected without central reading ${ }^{12,13}$. All adverse events occurring during the follow-up period were collected. Severe adverse events were defined as the occurrence of treatment interruption, hospitalization, disability, persistent damage, colectomy or death.

\section{Outcome measures}

The primary endpoint was steroid-free clinical remission at weeks 12-16. Clinical remission was defined as a partial Mayo Clinic score $\leq 2$, with a combined stool frequency and rectal bleeding subscore $\leq 1$. Secondary endpoints included clinical response, as defined by a reduction in the partial Mayo Clinic score of at least 3 points and a decrease of at least $30 \%$, with a decrease of at least 1 point on the rectal bleeding subscale or an absolute rectal bleeding score of 0 or 1 from the baseline score for UC patients, persistence of ustekinumab therapy, dose optimization at weeks 12 16, endoscopic changes between week 0 and weeks 12-16 and occurrence of any adverse event or severe adverse event. The use of either oral and intravenous steroids or budesonide was assessed at the baseline visit and at every subsequent visit. No standardized protocol of steroid tapering and immunomodulatory maintenance was set up.

\section{Statistical analysis}

The data were expressed as a number $(\%)$ for qualitative data and as the mean \pm standard deviation (SD) or median (interquartile range (IQR)) for quantitative data. Pre- and post-treatment 
outcomes and clinical, biological and endoscopic scores were compared between week 0 and weeks 12-16 using the $\mathrm{chi}^{2}$ test and Wilcoxon matched-pair signed-rank test whenever appropriate. All analyses were performed in an intent-to-treat manner. Patients who discontinued ustekinumab therapy before the week 12-16 visit were considered non-responders in all outcome measures. To identify predictors of steroid-free clinical remission at weeks 12-16, univariate analysis was conducted using the $\mathrm{chi}^{2}$ test. Subsequent multivariable analyses using binary logistic regression models were then performed and adjusted for using the above-mentioned variables with an ascending stepwise procedure using the Wald test. The odd ratios (ORs) are provided with 95\% confidence intervals (CIs). Quantitative values were converted to qualitative values using the difference from the median value in two distinct groups of equal size. Variables with $p<0.10$ in the univariate analysis were considered to be potential adjustment variables for the multivariable analysis. All analyses were two-tailed, and p values $<0.05$ were considered statistically significant. All statistical evaluations were performed using SPSS statistical software (SPSS Inc., v17, Chicago, IL, USA). 


\section{RESULTS}

\section{Study population}

A total of 103 patients with active UC treated with at least one dose of ustekinumab were included in 20 GETAID centres (Table 1). The median age and duration of UC at week 0 was 39.3 [IQR 29.1-52.3] years and 7.6 [3.6-12.9] years, respectively. Most of the patients had left-sided colitis $(41.8 \%)$ or pancolitis $(52.4 \%)$. A history of immunomodulator, anti-TNF or vedolizumab therapies was noted in $84.5 \%, 99.0 \%$ and $85.4 \%$ of the cases, respectively. The mean partial Mayo score was $5.9 \pm 1.9$ at week 0 . Endoscopic assessment was available in $93(90.3 \%)$ patients at week 0 with a mean value of $2.6 \pm 0.6$ for the Mayo Clinic endoscopic subscore and $5.1 \pm 1.3$ for the UCEIS, resulting in a mean total Mayo Clinic score of $8.5 \pm 2.1$. Concomitant steroid and immunosuppressant use was noted in $48.5 \%$ and $23.3 \%$ of the cases, respectively.

The ustekinumab induction therapy was delivered with a $6 \mathrm{mg} / \mathrm{kg}$ intravenous regimen in 93 $(90.3 \%)$ patients and with three scheduled subcutaneous injections of $90 \mathrm{mg}$ between week 0 and week 8 in 10 patients. The mean total dose of ustekinumab during the induction phase was $376 \pm$ $110 \mathrm{mg}$, corresponding to a dose of $5.4 \pm 1.3 \mathrm{mg} / \mathrm{kg}$. All patients were scheduled to receive a 90 mg dose at week 8 after the induction phase.

\section{Effectiveness of ustekinumab therapy at weeks 12-16}

All 103 patients were assessed at weeks 12-16, including $58(56.3 \%)$ at week 12, 26 $(25.2 \%)$ at week 14 and $19(18.4 \%)$ at week 16 . Two patients discontinued ustekinumab before the week 12-16 visit due to lack of efficacy and were referred for surgery. The primary endpoint, defined by steroid-free clinical remission at weeks $12-16$, was achieved in 36 patients (35.0\%) (Table 2). Among the 50 patients with concomitant steroids therapy at baseline, 14 (28\%) were in steroids 
free clinical remission at weeks 12-16. Clinical remission, defined by a partial Mayo Clinic score $\leq 2$ with a combined stool frequency and rectal bleeding subscore $\leq 1$, was achieved in $41(39.8 \%)$ patients. Clinical response was observed in 55 (53.4\%) patients at week 12-16. The global partial Mayo Clinic score decreased between week 0 and weeks $12-16$ by a total of $2.3 \pm 2.7$ points $(p=$ 0.04), whereas the global CRP level decreased by $7.6 \pm 33.8 \mathrm{mg} / \mathrm{L}(\mathrm{p}<0.001)$. Regarding patientreported outcomes (PROs) derived from the Mayo Clinic rectal bleeding and stool frequency subscores, rectal bleeding and stool frequency subscores of 0 were noted in $20(19.4 \%)$ patients, whereas a rectal bleeding score of 0 and a stool frequency subscore of 0 or 1 were noted in 41 (39.8\%) patients. Due to a lack of efficacy, 16 (15.5\%) patients were optimized to four weekly 90 mg subcutaneous injections of ustekinumab before the week 12-16 visit. At the week 12-16 visit, ten $(9.7 \%)$ patients discontinued ustekinumab due to lack of efficacy.

\section{Endoscopic activity}

Among the 93 patients with an assessment of endoscopic activity at week 0, $49(47.6 \%)$ were also re-evaluated at weeks $12-16$. The UCEIS significantly decreased from $5.0 \pm 1.2$ to $3.8 \pm$ $1.9(\mathrm{p}<0.001)$ and the Mayo Clinic endoscopic subscore decreased from $2.7 \pm 0.5$ to $2.2 \pm 1.0(\mathrm{p}$ $=0.001)$. At weeks 12-16, eight out of $49(16.3 \%)$ patients had a UCEIS score of 0 or 1 , and nine (18.4\%) had a Mayo Clinic endoscopic subscore of 0 or 1 . Among patients with steroid-free clinical remission, the UCEIS and Mayo Clinic endoscopic subscore also decreased from $4.7 \pm 1.3$ to 1.8 $\pm 1.4(\mathrm{p}<0.001)$ and from $2.5 \pm 0.5$ to $1.5 \pm 1.1(\mathrm{p}=0.001)$, respectively. In patients without steroid-free clinical remission, the decrease was much lower with a decrease in the UCEIS from $5.2 \pm 1.1$ to $4.7 \pm 1.2(\mathrm{p}=0.006)$ and non-significant in the Mayo Clinic Endoscopic subscore from $2.8 \pm 0.4$ to $2.5 \pm 0.8(\mathrm{p}=0.06)$.

\section{Predictors of steroid-free clinical remission at weeks 12-16}


Predictors of steroid-free clinical remission at weeks 12-16 were assessed with univariate and multivariable analyses (Table 3). In univariate analysis, the presence of steroid-free clinical remission was decreased with a partial Mayo Clinic score $>6(p=0.003)$, total Mayo Clinic score $>8(\mathrm{p}=0.004)$, serum albumin level $<37 \mathrm{~g} / \mathrm{L}(\mathrm{p}=0.03)$, and history of both exposure to anti-TNF and vedolizumab therapies $(\mathrm{p}=0.001)$. In multivariable analysis, steroid-free clinical remission at weeks $12-16$ was decreased in patients with a partial Mayo Clinic score $>6(\mathrm{OR}=0.10,95 \% \mathrm{CI}$ $[0.01-0.90] ; \mathrm{p}=0.04)$ and history of both exposure to anti-TNF and vedolizumab therapies $(\mathrm{OR}=$ $0.03,95 \%$ CI $[0.01-0.42 ; \mathrm{p}=0.01)$.

\section{Safety}

The analysis of adverse events was performed for all patients who received at least one dose of ustekinumab (Table 4). Adverse events occurred in eight (7.8\%) patients, including three patients with exacerbation of UC leading to hospitalization, one patient with arthralgia, one patient with symptomatic urolithiasis, one with pneumonia, one with a dental abscess and one with a skin rash. Serious adverse events occurred in four (3.9\%) cases, including three cases of exacerbation of UC and one case of pneumonia leading to hospitalization. Adverse events led to ustekinumab withdrawal in three $(2.9 \%)$ patients. 


\section{DISCUSSION}

In this first large real-world study of ustekinumab in treating UC, we evaluated the effectiveness and safety of short-term induction with ustekinumab in patients with UC that have failed multiple biologics. The rates of steroid-free clinical remission and clinical remission were $35 \%$ and $40 \%$ at weeks $12-16$, respectively. This was associated with evidence of biological and endoscopic response as well as a good safety profile.

Ustekinumab has been evaluated in patients with moderate-to-severe UC in one randomized placebo-controlled trial ${ }^{14}$. In the UNIFI trial, the efficacy and safety of ustekinumab were evaluated in 961 patients at week 8 after induction therapy with intravenous ustekinumab or placebo and at week 44 for maintenance therapy after responders were randomly assigned to subcutaneous injections of ustekinumab or placebo. Clinical remission at week 8 among patients who received intravenous ustekinumab at a dose of $130 \mathrm{mg}(16 \%)$ or $6 \mathrm{mg}$ per kilogram (16\%) was significantly higher than that among patients who received placebo $(5 \%)$. The percentage of patients who had clinical remission at week 44 was significantly higher among patients assigned to subcutaneous ustekinumab treatment every 12 weeks $(38 \%)$ or 8 weeks $(44 \%)$ as compared to those assigned to placebo treatment (24\%). It should be noted that $50 \%$ and $15 \%$ of patients included in the UNIFI trial had experienced previous failure with an anti-TNF agent or vedolizumab, respectively. In UNIFI, ustekinumab was effective for induction and maintenance treatment in patients with previous exposure to biologics as well as in bio-naïve patients. But, as previously observed with other drugs, the rates of the different efficacy outcomes were consistently lower for patients with previous failure while on a biologic in each treatment group. In our cohort, the condition of the study population was more severe and refractory than in the UNIFI trial, with $99 \%$ and $85 \%$ of patients experiencing failure with an anti-TNF and vedolizumab, respectively. 
We still observed a high rate of steroid-free clinical remission in one-third of patients. No data considering clinical remission according to the partial Mayo Clinic score are currently available from the UNIFI trial for comparison. It is conceivable that our study may be counterbalanced by less strictly defined clinical outcome measurements.

As recognized by the STRIDE committee and the US Food and Drug Administration's recognition, PROs, such as resolution of rectal bleeding and normalization of bowel habits, should be a therapeutic target for $\mathrm{UC}^{15}$. Complete normalization of rectal bleeding (rectal bleeding subscore of 0 ) and stool frequency was noted in $19 \%$ of patients, whereas normalization of rectal bleeding with a stool frequency subscore of 0 or 1 was noted in $40 \%$ of patients. Another therapeutic goal in patients with UC is to induce endoscopic improvement. Inducing endoscopic improvement is another main therapeutic goal, with better subsequent long-term outcomes in patients with UC achieving mucosal healing (16). Our study demonstrated a clinical improvement of both the Mayo Clinic endoscopic subscore and UCEIS. We acknowledge a recruitment bias in the endoscopic assessment. Indeed, only approximatively half of patients had endoscopic assessment of mucosal healing at the end of the induction phase. Furthermore, the rate of patients with either the Mayo Clinic endoscopic subscore or UCEIS of 0 or 1 was close to those reported in the UNIFI trial. Those data emphasize the objective improvement of patients with UC treated with ustekinumab and show that ustekinumab is an efficient therapeutic option in bio-failure patients.

Due to a lack of efficacy, $15 \%$ of patients were optimized to four weekly $90 \mathrm{mg}$ subcutaneous doses of ustekinumab over the 12-16-week follow-up period. Even though no similar data over the induction period are available in Crohn's disease, some retrospective studies reported that up to $50 \%$ of patients need dose escalation to optimize their primary response to ustekinumab 
induction therapy ${ }^{16}$. The need and effectiveness of ustekinumab optimization to every 4 weeks dosing will require further study.

A decreased partial Mayo Clinic score $>6$ and history of both exposure to anti-TNF and vedolizumab therapies were identified as inversely associated with the occurrence of steroid-free remission at weeks 12-16. In both Crohn's disease and UC phase 3 clinical trials, the rates of clinical response and remission at induction were higher in patients who had failed or were intolerant to conventional therapy as compared to patients who had failed anti-TNF therapy ${ }^{14,17}$. In Crohn's disease, there are no data from observational studies comparing the response to ustekinumab between anti-TNF naïve and exposed patients, since all patients included in these studies had failed or were intolerant to anti-TNF therapy ${ }^{18}$. As previously observed in Crohn's disease, concomitant use of an immunomodulator was not associated with the short-term efficacy of ustekinumab in UC.

The safety of ustekinumab in patients with chronic immune-mediated inflammatory diseases (IMIDs) has been extensively evaluated in numerous clinical trials and in post-marketing observational studies included in controlled trials ${ }^{19-21}$. In the UNITI trial, the incidence of serious adverse event with ustekinumab was similar to that with placebo. The most common adverse events were pyrexia, headache and nasopharyngitis; they were mild and did not require withdrawal of ustekinumab ${ }^{14}$. In the present study, short-term use of ustekinumab was found to be safe and welltolerated, with four serious adverse events. No injection site reactions, deaths or malignancies were reported.

Our study has some limitations. Primarily, this was a retrospective analysis, which introduces the possibility of recall bias. We also acknowledge that during the study period, 
ustekinumab could have been maintained because of a lack of other existing drugs to avoid surgery. We attempted to minimize this by using stringent, well-validated and objective definitions of clinical effectiveness as described by internationally endorsed recommendations ${ }^{15}$. Also, this study was conducted only over the induction period cohort without a control group. The biomarkers and pharmacokinetics of ustekinumab could not be assessed. However, this first observational cohort has some strengths, as it is a multicentre national study design, including all consecutive patients with UC treated with ustekinumab.

In conclusion, this first large multicentre real-world study of ustekinumab has shown that it is effective in inducing steroid-free clinical remission in one-third of patients with refractory UC with a good safety profile. Clinical severity and history of both exposure to anti-TNF and vedolizumab therapies are associated with a lower probability of steroid-free clinical remission. 


\section{TABLE LEGENDS}

Table 1: Demographic, disease characteristics and medication histories of the 103 patients with ulcerative colitis at the time of introduction of ustekinumab therapy

Table 2: Outcome measures at weeks $12-16$ for ustekinumab therapy in 103 patients with ulcerative colitis (RBS: rectal bleeding score; SFS: stool frequency score)

Table 3: Predictors of steroid-free remission at week 12-16 in 103 patients with ulcerative colitis treated with ustekinumab

Table 4: Adverse events affecting 103 patients with ulcerative colitis treated with ustekinumab therapy 


\section{REFERENCES}

1. Danese S, Fiocchi C. Ulcerative colitis. N Engl J Med 2011;365:1713-1725.

2. Ungaro R, Mehandru S, Allen PB, et al. Ulcerative colitis. Lancet Lond Engl 2017;389:1756$\underline{1770 .}$

3. Lichtenstein GR, Feagan BG, Cohen RD, et al. Serious infection and mortality in patients with Crohn's disease: more than 5 years of follow-up in the TREAT ${ }^{\mathrm{TM}}$ registry. Am J Gastroenterol 2012;107:1409-1422.

4. Toruner M, Loftus EV Jr, Harmsen WS, et al. Risk factors for opportunistic infections in patients with inflammatory bowel disease. Gastroenterology 2008;134:929-36. Gastroenterology 2008;134:929-36.

5. Pouillon L, Lamoureux A, Pineton de Chambrun G, et al. Dose de-escalation to adalimumab $\underline{40 \mathrm{mg} \text { every three weeks in patients with inflammatory bowel disease-A multicenter, }}$ retrospective, observational study. Dig Liver Dis Off J Ital Soc Gastroenterol Ital Assoc Study Liver 2019;51:236-241.

6. Singh S, Fumery M, Sandborn WJ, et al. Systematic review with network meta-analysis: firstand second-line pharmacotherapy for moderate-severe ulcerative colitis. Aliment Pharmacol Ther 2018;47:162-175.

7. Peyrin-Biroulet L, Danese S, Argollo M, et al. Loss of Response to Vedolizumab and Ability of Dose Intensification to Restore Response in Patients With Crohn's Disease or Ulcerative Colitis: A Systematic Review and Meta-analysis. Clin Gastroenterol Hepatol Off Clin Pract J Am Gastroenterol Assoc 2019;17:838-846.e2. 
8. Ochsenkühn, Thomas, Tillack C, Szokodi D, et al. Clinical outcomes with ustekinumab as $\underline{\text { rescue treatment in therapy-refractory or therapy-intolerant ulcerative colitis. United Eur }}$ Gastroenterol J 2019;8:91-98.

9. Amiot A, Grimaud J-C, Peyrin-Biroulet L, et al. Effectiveness and Safety of Vedolizumab Induction Therapy for Patients With Inflammatory Bowel Disease. Clin Gastroenterol Hepatol Off Clin Pract J Am Gastroenterol Assoc 2016;14:1593-1601.e2.

10. Amiot A, Serrero M, Peyrin-Biroulet L, et al. One-year effectiveness and safety of vedolizumab therapy for inflammatory bowel disease: a prospective multicenter cohort study. Aliment Pharmacol Ther 2017:in press.

11. Amiot A, Serrero M, Peyrin-Biroulet L, et al. Three-year effectiveness and safety of vedolizumab therapy for inflammatory bowel disease: a prospective multi-centre cohort study. Aliment Pharmacol Ther 2019;50:40-53.

12. Rutgeerts $\mathrm{P}$, Sandborn WJ, Feagan BG, et al. Infliximab for induction and maintenance therapy for ulcerative colitis. N Engl J Med 2005;353:2462-2476.

13. Travis SPL, Schnell D, Krzeski P, et al. Reliability and initial validation of the ulcerative $\underline{\text { colitis endoscopic index of severity. Gastroenterology 2013;145:987-995. }}$

14. Sands BE, Sandborn WJ, Panaccione R, et al. Ustekinumab as Induction and Maintenance Therapy for Ulcerative Colitis. N Engl J Med 2019;381:1201-1214.

15. Peyrin-Biroulet L, Sandborn W, Sands BE, et al. Selecting Therapeutic Targets in Inflammatory Bowel Disease (STRIDE): Determining Therapeutic Goals for Treat-to-Target. Am J Gastroenterol 2015;110:1324-1338. 
16. Ma C, Fedorak RN, Kaplan GG, et al. Long-term Maintenance of Clinical, Endoscopic, and $\underline{\text { Radiographic Response to Ustekinumab in Moderate-to-Severe Crohn's Disease: Real-world }}$ Experience from a Multicenter Cohort Study. Inflamm Bowel Dis 2017;23:833-839.

17. Feagan, Sandborn WJ, Gasink C, et al. Ustekinumab as induction and maintenance therapy for Crohn's disease. N Engl J Med 2016;375:1946-60.

18. Barré A, Colombel J-F, Ungaro R. Review article: predictors of response to vedolizumab and ustekinumab in inflammatory bowel disease. Aliment Pharmacol Ther 2018;47:896-905.

19. Papp K, Gottlieb AB, Naldi L, et al. Safety Surveillance for Ustekinumab and Other Psoriasis Treatments From the Psoriasis Longitudinal Assessment and Registry (PSOLAR). J Drugs Dermatol JDD 2015;14:706-714.

20. Engel T, Yung DE, Ma C, et al. Effectiveness and safety of Ustekinumab for Crohn's disease; systematic review and pooled analysis of real-world evidence. Dig Liver Dis Off J Ital Soc Gastroenterol Ital Assoc Study Liver 2019;51:1232-1240.

21. López-Ferrer A, Laiz A, Puig L. The safety of ustekinumab for the treatment of psoriatic arthritis. Expert Opin Drug Saf 2017;16:733-742. 


\section{APPENDIX: Members of the UC-USK-GETAID study group}

Aurélien Amiot, Charlotte Gagnière, Jenny Tannoury. Henri Mondor Hospital, APHP, EC2M3EA7375, Paris Est-Créteil University, Creteil, F-94010 France

Jérôme Filippi, Xavier Hebuterne. Nice University Hospital, University of Nice Sophia-Antipolis, Nice, France

Vered Abitbol. Cochin Hospital, University Paris 5 Descartes, Paris, France.

Guillaume Cadiot, Hedia Brixi. Reims University Hospital, Reims, France.

David Laharie, Pauline Rivière, Florian Poullenot. University Hospital of Bordeaux, Hôpital HautLévêque, Bordeaux, France

Melanie Serrero. Hôpital Nord, Centre d'investigation clinique Marseille Nord, Université Méditerranée, Marseille, France

Romain Altwegg, Guillaume Pineton de Chambrun. Hôpital Saint-Eloi, University Hospital of Montpellier, Montpellier, France

Yoram Bouhnik, Xavier Treton, Carmen Stefanescu. Beaujon Hospital, University Paris 7 Denis Diderot, Clichy, France

Laurent Peyrin-Biroulet, Camille Zallot. INSERM U954, Université de Lorraine, Nancy, France

Cyrielle Gilletta. Toulouse University Hospital, Toulouse, France.

Xavier Roblin. Saint-Etienne University Hospital, Saint-Etienne, France.

Lucine Vuitton. Besançon University Hospital, Besançon, France. 


\begin{abstract}
Anne Bourrier, Laurent Beaugerie, Philippe Seksik, Harry Sokol, Julien Kirchgesner. AP-HP, Hôpital Saint-Antoine, F-75012, ERL 1057 INSERM/UMRS 7203, UPMC Université Paris 6, Paris, France

Stephane Nancey Gilles Boschetti, Bernard Flourié, Claire Gay, Pauline Danion, Chloe Venturin. Hospices Civils de Lyon and University Claude Bernard Lyon 1, Pierre-Benite, France.

Jean-Marc Gornet, Matthieu Allez, Clotilde baudry. Saint-Louis University Hospital, Paris, France

Stephane Nahon. Monterfermeil Hospital, Montfermeil, France

Guillaume Bouguen. Pontchaillou Hospital and Rennes University, Rennes, France

Stephanie Viennot. Caen University Hospital, Caen, France

Benjamin Pariente, Maria Nachury, Pauline Wils. Huriez Hospital, Université of Lille, Lille, France.
\end{abstract}

Mathurin Fumery, Franck Brazier, Clara Yzet. Amiens University Hospital, Amiens, France 
Table 1: Demographic, disease characteristics and medication histories of the 103 patients with ulcerative colitis at the time of introduction of ustekinumab therapy

\begin{tabular}{|c|c|}
\hline Characteristic & Patients with ulcerative colitis, $n=103$ \\
\hline Age, years & $39.3[29.1-52.3]$ \\
\hline Male gender, $\mathrm{n}(\%)$ & $62(60.2 \%)$ \\
\hline BMI, $\mathrm{kg} / \mathrm{m}^{2}$ & $24.3 \pm 5.9$ \\
\hline \multicolumn{2}{|l|}{ Smoking habits, $\mathrm{n}(\%)$} \\
\hline Past smoker & $30(29.1 \%)$ \\
\hline Active smoker & $7(6.8 \%)$ \\
\hline Duration of disease, years & $7.6[3.6-12.9]$ \\
\hline \multicolumn{2}{|l|}{ Age at diagnosis } \\
\hline $\mathrm{A} 1: \leq 16$ years & $8(7.8 \%)$ \\
\hline A2: $17-40$ years & $68(66.0 \%)$ \\
\hline A3: $>40$ years & $27(26.2 \%)$ \\
\hline \multicolumn{2}{|l|}{ Location } \\
\hline Proctitis & $6(5.8 \%)$ \\
\hline Left-sided colitis & $43(41.8 \%)$ \\
\hline Extensive colitis & $54(52.4 \%)$ \\
\hline \multicolumn{2}{|l|}{ Prior medications exposure } \\
\hline Immunosuppressant & $87(84.5 \%)$ \\
\hline Purine analogues & $85(82.5 \%)$ \\
\hline Methotrexate & $25(24.3 \%)$ \\
\hline anti-TNF therapy & $102(99.0 \%)$ \\
\hline One anti-TNF agent & $30(29.1 \%)$ \\
\hline$\geq 2$ anti-TNF agents & $72(69.9 \%)$ \\
\hline Vedolizumab & $88(85.4 \%)$ \\
\hline Tofacitinib & $10(9.7 \%)$ \\
\hline \multicolumn{2}{|l|}{ Clinical and endoscopic activity at week 0} \\
\hline Partial Mayo Clinic score & $5.9 \pm 1.9$ \\
\hline Mayo endoscopic subscore $(n=93)$ & $2.6 \pm 0.6$ \\
\hline
\end{tabular}




\begin{tabular}{|l|c|}
\hline Total Mayo Clinic score $(\mathrm{n}=93)$ & $8.5 \pm 2.1$ \\
Ulcerative colitis Endoscopic Index of Severity $(\mathrm{n}=93)$ & $5.1 \pm 1.3$ \\
\hline Concomitant medications & $41(39.8 \%)$ \\
Glucocorticoids only & $15(14.6 \%)$ \\
Immunosuppressants only & $9(8.7 \%)$ \\
Glucocorticoids and immunosuppressants & $38(36.9 \%)$ \\
No glucocorticoids or immunosuppressants & $93(90.3 \%)$ \\
\hline Ustekinumab therapy & $10(9.7 \%)$ \\
Intravenous 6-mg/kg induction & $376 \pm 110$ \\
Subcutaneous 270-mg induction & $5.4 \pm 1.3$ \\
Total induction dose & $9034 \pm 3244$ \\
Total induction dose per kg & $13.1 \pm 1.7$ \\
\hline Biologic variables & $7.1[3.1-15.0]$ \\
Hemoglobin level, g/dL & $37.2 \pm 4.9$ \\
Leukocytes count, 109/L & \\
CRP level, mg/L & \\
serum albumin, g/L & \\
\hline
\end{tabular}

BMI: body mass index; CRP: high sensitivity C-reactive protein; TNF: tumor necrosis factor- $\alpha$.

Variables are presented as $\mathrm{n}(\%)$, mean \pm standard deviation or median [interquartile range]. 
Table 2: Outcome measures from week 6 to week 54 for vedolizumab therapy in 173 patients with Crohn's disease and 121 patients with ulcerative colitis.

\begin{tabular}{|c|c|c|c|c|}
\hline & $\begin{array}{l}\text { No history of both exposure } \\
\frac{\text { to anti-TNF and vedolizumab }}{\text { therapies }}\end{array}$ & $\begin{array}{l}\text { History of both exposure to } \\
\underline{\text { vedolizumab and anti-TNF }} \\
\underline{\text { therapies }}\end{array}$ & $\begin{array}{l}\text { Overall study } \\
\text { population } \\
(\mathrm{n}=103)\end{array}$ & $\mathrm{P}$ \\
\hline Clinical response & $13(86.7 \%)$ & $42(47.7 \%)$ & $55(53.4 \%)$ & 0.005 \\
\hline Steroid-free clinical remission & $12(80.0 \%)$ & $24(27.3 \%)$ & $36(35.0 \%)$ & $<0.001$ \\
\hline Clinical remission & $13(86.7 \%)$ & $28(31.8 \%)$ & $41(39.8 \%)$ & $<0.001$ \\
\hline RBS 0 and SFS 0-1 & $11(73.3 \%)$ & $9(10.2 \%)$ & $20(19.4 \%)$ & $<0.001$ \\
\hline RBS 0 and SFS 0 & $13(86.7 \%)$ & $28(31.8 \%)$ & $41(39.8 \%)$ & $<0.001$ \\
\hline
\end{tabular}

Clinical remission was defined as a partial Mayo Clinic score $<3$ with a combined stool frequency subscore (SFS) and rectal bleeding subscore (RBS) of $\leq 1$. Clinical response was defined as a reduction in the partial Mayo Clinic score of at least 3 points and a decrease of at least $30 \%$, with a decrease of at least 1 point on the rectal bleeding subscale or an absolute rectal bleeding score of 0 or 1 from the week 0 baseline score for patients with ulcerative colitis. The proportions of patients who met the criteria for the latter end points during the present trial of maintenance therapy were analyzed with the reference to the whole population included at week 0 . 
Table 3: Predictors of steroid-free remission at week 12-16 in 103 patients with ulcerative colitis treated with ustekinumab

\begin{tabular}{|l|c|c|c|}
\hline \multirow{2}{*}{ Risk factors } & Univariate analysis & \multicolumn{2}{|c|}{ Multivariate analysis } \\
\cline { 2 - 4 } & $\underline{\text { OR }(95 \% \mathrm{CI})}$ & $\underline{\text { P value }}$ & \multicolumn{2}{|c|}{ OR $(95 \% \mathrm{CI})$} \\
\hline Partial Mayo Clinic score $>6$ & $0.24[0.10-0.61]$ & 0.003 & $0.10[0.01-0.90]$ \\
\hline Total Mayo Clinic score $>8$ & $0.26[0.10-0.65]$ & 0.004 & - \\
\hline Serum albumin level $<37 \mathrm{~g} / \mathrm{L}$ & $0.19[0.05-0.83]$ & 0.03 & NS \\
\hline History of anti-TNF and vedolizumab & $0.10[0.03-0.38]$ & 0.001 & $0.03[0.01-0.42]$ \\
\hline
\end{tabular}

Odd ratio (OR) with 95\% confidence interval (CI) was estimated using Cox models 
Table 4: Adverse events affecting 103 patients with ulcerative colitis treated with ustekinumab therapy

\begin{tabular}{|c|c|}
\hline Event & Ulcerative colitis \\
& $(\mathrm{n}=103)$ \\
\hline Number of adverse events & $8(7.8 \%)$ \\
Arthralgia & 1 \\
IBD exacerbation & 3 \\
Pneumonia & 1 \\
Dental abscess & 1 \\
Skin rash & 1 \\
Symptomatic urolithiasis & 1 \\
\hline Any serious adverse event* & $4(3.9 \%)$ \\
\hline Any cancer & 0 \\
\hline
\end{tabular}

*A serious adverse event was defined as any adverse event when leading to treatment interruption, hospitalization, disability or persistent damage, colectomy and death. 


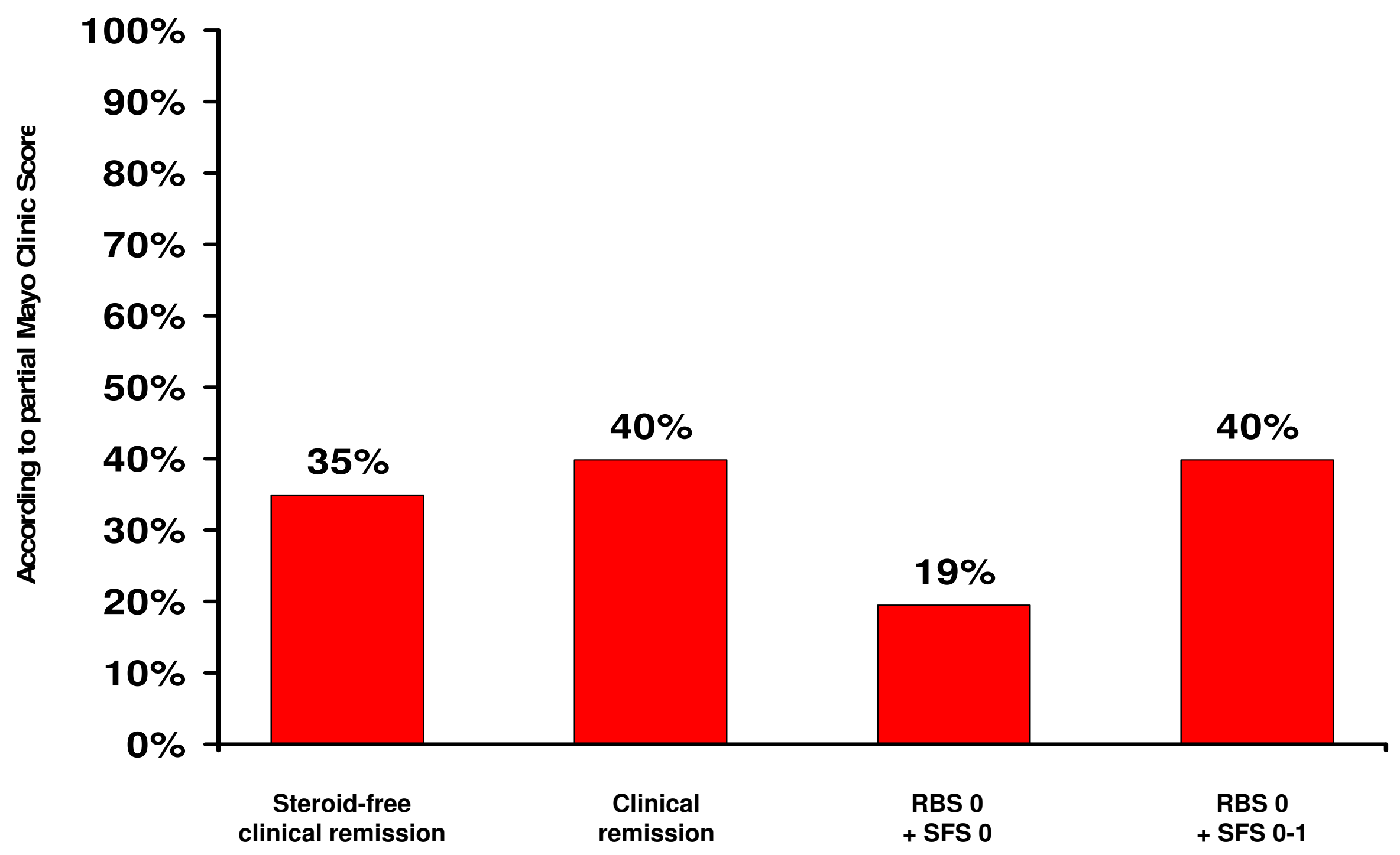

